\title{
PLASMACYTOMA OF MANDIBLE: A CASE REPORT.
}

Vaibhav Mane, R. T. Joshi.

1. Assistant Professor, Department of Pathology, Bharati Vidyapeeth Medical College and Hospital. Sangli, Maharashtra.

2. Professor, Department of Pathology, Bharati Vidyapeeth Medical College and Hospital. Sangli. Maharashtra.

\section{CORRESPONDING AUTHOR}

Dr. Vaibhav P. Mane

Vaishnavi Pathology Laboratory, Shop No.2, Kore House, Vishrambag, Sangli-416415, Maharashtra.

E-mail: vaishnavilab@rediffmail.com

Ph: 00919422041490.

ABSTRACT: BACKGROUND AND AIM: Extramedullary Plasmacytomas (EMP) are rare tumors accounting for $0.4 \%$ of all head and neck malignancies. The patients ranged from 34 to 76 years, there was a marked preponderance of males. Chronic, non-painful swelling of the posterior portion of mandible with is the commonest symptom. Monoclonal immunoglobulin was initially detected in $42 \%$ of the evaluated patients. The majority of patients were treated with radiation therapy. $17 \%$ of the patients progressed to multiple myeloma within 1 year.

A $60 \mathrm{yr}$ old male, chronic tobacco sniffer presented with swelling posterior end mandible. Radiography revealed a multilocular radiolucent lesion in the mandibular posterior region. Bone marrow aspiration revealed a plasma cell infiltrate of less than $3 \%$ of all nucleated cells. Microscopically the tumour shows mature, immature, typical, atypical, binucleate plasma cells in sheets. A histological diagnosis of plasmacytoma was made. CONCLUSION: We report a case of extramedullary plasmacytoma ( EMP) of the mandible in a 60 year old male, who was a chronic tobacco sniffer. The case demonstrates the multidisciplinary approach required for the optimal diagnosis and management of such tumors and proposes chronic irritation as one of the etiological factors for EMP.

KEYWORDS: Plasma cell neoplasm, bone, solitary plasmacytoma, Multiple myeloma; plasmacytoma

INTRODUCTION: Extramedullary Plasmacytomas (EMP) are rare tumors accounting for $0.4 \%$ of all head and neck malignancies. Review of the literature disclosed the following characteristics regarding the clinical course and prognosis. The patients ages ranged from 34 to 76 years, with a mean of 53 years; there was a marked preponderance of males. The site of predilection was the posterior portion of the mandible. The common symptom was a non-painful swelling of the mandible of long duration, and radiological features were non-specific. Monoclonal immunoglobulin was initially detected in $42 \%$ of the evaluated patients. The majority of patients were treated with radiation therapy with a mean dose of 48Gy with or without surgery. The period of follow-up ranged from 4 months to 12 years, and $17 \%$ of the patients progressed to multiple myeloma within 1 year.

A plasmacytoma is a discrete, solitary mass of neoplastic monoclonal plasma cells in either bone or soft tissue (extramedullary).Solitary plasmacytomas can be divided into 2 groups according to location: 
- Plasmacytoma of the skeletal system (SBP).

- Extramedullary Plasmacytoma (EMP)

\section{DIAGNOSTIC CRITERIA FOR SOLITARY BONE PLASMACYTOMA (SBP) $[1,2,6,8,9]$}

- Single area of bone destruction due to clonal plasma cells

- Bone Marrow Plasma Cell infiltration not exceeding 5\% of all nucleated cells.

- Absence of osteolytic bone lesions or other tissue involvement (no evidence of myeloma)

- Absence of anemia, hypercalcemia, or renal impairment attributable to myeloma

- Low, if present, concentrations of serum or urine monoclonal protein

- Preserved levels of uninvolved immunoglobulins.

The present study was done as incidence of extramedullary plasmacytomas are very low and to compare the findings with that of others.

CASE DESCRIPTION: A 60-year-old male patient consulted with the primary complaint of slowly developed swelling in his mandible. Past history was not contributory. He was a chronic tobacco sniffer.

Clinical examination revealed a tender swelling at posterior angle of mandible measuring $5 \times 3 \times 1 \mathrm{~cm}$.

Haematological laboratory findings revealed WBC as $6.5 \times 103 / \mathrm{uL}, \mathrm{RBC} 4.10 \times 105 / \mathrm{uL}$, HGB 7.9 g/dL, P 82 \%, L 14 \%, M 02 \%, E $02 \%$. and ESR was 60 mm/h.

Routine blood tests and serum biochemistry including calcium, phosphorus, blood urea nitrogen, urea, uric acid and creatinine were all within reference range. Both serum myeloma proteins and urine Bence- Jones proteins were negative. Serum and urine electrophoresis did not reveal M component.

Bone marrow aspiration revealed a plasma cell infiltrate of less than $3 \%$ of all nucleated cells.

Radiography revealed a multilocular radiolucent lesion in the mandibular posterior region, which was ill-defined and caused deformation in cortical bone. There were no other bony changes in his skull radiograms. Chest radiograph, total body skeletal survey, showed no systemic lesion.

FNAC NOT DONE: Excision biopsy is done. Post operative the patient was asymptomatic.There is no history of recurrence.

The tumour tissue was received in form of multiple pieces of fibromuscular tissue along with irregular tumour mass which has ragged margin and gray white cut surface.

Microscopically the tumour shows mature, immature, typical, atypical, binucleate plasma cells in sheets. Areas of haemorrhage are also noted Adjacent skeletal muscle is free of tumour infiltration.( Fig . 1)

A histological diagnosis of plasmacytoma was made.

DISCUSSION: SPB is tumor of plasma cells, which manifests itself as a single osteolytic lesion without plasmocytosis of bone marrow and constitutes approximately $3 \%$ of all plasma 
containing tumors $[1,2,9]$ SPB is more prevalent in males than females, the ratio being $2: 1[1,8,9$ ]

The most common sites of SPB were long bones and vertebrae. It rarely involves jaws and when it was seen, only $4.4 \%$ of SPB occur in the mandible, most commonly in the bone marrow-rich areas of the body, angulus and ramus mandible $[1,3,9,10]$.

Most common clinical symptoms of SPB are pain in the jaws and teeth, paraesthesia, anesthesia, mobility and migration of the teeth, haemorrhage, swelling in hard and soft tissues and pathological fractures. $[1,8]$

In our case, the lesion was located in the posterior part of the mandible. A study by Pisano et al [2] containing 13 cases of SPB, showed that nine lesions were located posterior to the premolars and only one case was anterior but distal to the canine. A study carried out by Marick et al [3] which consisted of 21 cases of SPB showed that in 15 cases, the lesion affected the maxilla more than the mandible and despite the reported female predominance in the literature, males were predominant. The male/female ratio was 2:1. In our case, swelling was the major symptom and pain was present but paraesthesia was not reported. Radiographically, SPB was seen as a well defined, unilocular or multilocular destructive lesion with lack of any sign of bone reaction $[5,6,8$,$] . But in our case, only unilocular lesion was noted.$

There is a possibility of transformation of SPB and EMP to MM. This possibility was higher in SPB than EMP. Clinical investigations conclude that $35-85 \%$ of SPB cases were transformed to $\mathrm{MM}$ in a period of couple of months to a few years. But it is not possible to predict which case may transform, so after treatment, SPB cases must be followed up with routine laboratory monitoring of immunoglobulins and monoclonal proteins in serum and Bence-Jones proteins in urine In our case, when the patient first consulted our clinic for the jaw lesion, bone marrow examination results were normal.

Plasma cell neoplasms appear as sheets of plasma cells and are indistinguishable histologically. Clinical signs were also the same. Distinguishing one from the other was critical to treatment and survival. According to the description of dysplastic behaviour of plasmacytoma by Sukpaninchnant et al [6] minimal dysplasia was defined as most of the plasma cells being mature and plasmoblasts (cells with nucleoli) accounting for less than $10 \%$ of cells, whereas marked dysplasia was defined as plasmoblasts consisting of greater than $50 \%$ of tumour cells. Our case was judged as minimal dysplastic as the histopathological results indicated mature plasma cells. The course of SPB was relatively benign. Nevertheless, prognosis of SPB is poorer than EMP; $58 \%$ of cases progress to MM and survival at 10 years is $16 \%$ in $\mathrm{SPB}[5,6,7,8]$,$) . The average$ outliving is over 90 months.

CONCLUSION: In present case a $60 \mathrm{yr}$ old male chronic tobacco sniffer presented with swelling in the mandible. On laboratory and radiological investigations, biopsy was done which showed sheets of mature immature plasma cells. Bone marrow aspiration showed plasma cells $3 \%$.So the diagnosis of extramedullary plasmacytoma was done.

The course was relatively benign, however some cases may progress to multiple myeloma. The case demonstrates the multidisciplinary approach required for the optimal diagnosis and management of such tumors. 


\section{REFERENCES:}

1. Seoane J, Aguirre-Urizar JM, Esparza-Gomez G, Suarez-Cunqueiro M, Campos-Trapero J, Pomareda M. The spectrum of plasma cell neoplasia in oral pathology. Med Oral 2003;8:269-80.

2. Pisano JJ, Coupland R, Chen SY, Miller AS. Plasmacytoma of the oral cavity and jaws. A clinopathological study of 13 cases. Oral Surg Oral Med Oral Pathol Oral Radiol Endod 1997; 83:265-71.

3. Marick EL, Vencio EF, Inwards CY, Unni KK, Nascimento AG. Myeloma of the jaw bones: a clinopathological study of 33 cases. Head Neck 2003; 25:373-81.

4. Bolek WT, Marcus RB, Mendenhall NP. Solitary plasmacytoma of bone and soft tissues. Int J Radiation Oncology Biol Phys 1996; 36:329-3.

5. Muzio LL, Pannone G, Bucci P. Early clinical diagnosis of solitary plasmocytoma of the jaws: a case report with a six year follow-up. Int J Oral Maxillofac Surg 2001; 30:558-60.

6. Sukpaninchnant S, Cousar JB, Leelasiri A, Graber SE, Greer JP, Collins RD. Diagnostic criteria and histological grading in multiple myeloma: histologic and immunohistologic analysis of 176 cases with clinical correlation. Hum Pathol

7. 1994; 25:308-18. James Corwin, Robert D.Lindberg : Solitary Plasmacytoma of Bone VSExtramedullary Plasmacytoma and their relationship to Multiple Myeloma Cancer 43 : $1007-1013,1979$.

8. Suzanne R Fanning : Plasmacytoma Extramedullary : EMedicine Haematology

9. M.Hughes, R.Soutar, H.Lucraft,Owen, J.Bird. Guidelines on the diagnosis and management of solitary plasmacytoma of bone, extramedullary plasmacytoma and multiple solitary plasmacytoma ; 2009 update.Prepared by a working group of UKMF guideline Working Group.

10. Emin Murat Canger, Peruze Celenk, et al ; Mandibular involvement solitary plasmacytoma a case report .Medicina Oral, Patologia Oral y Cirugia Bucal ( Internet)

LOW POWER VIEW : Sheets of plasma cells

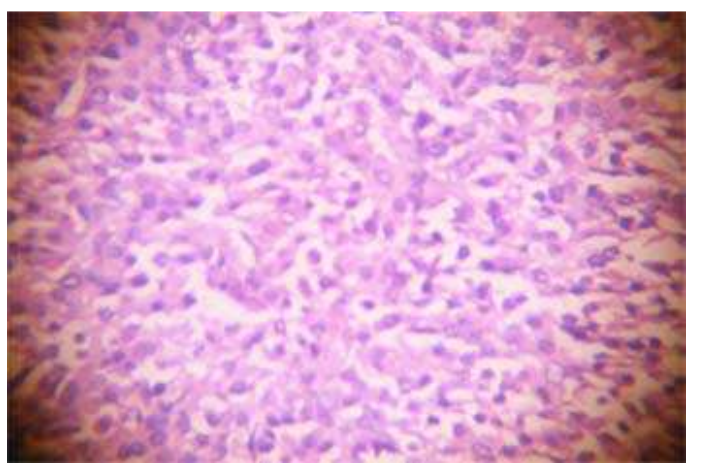

HIGH POWER VIEW : Sheets of mature, immature and binucleate plasma cell

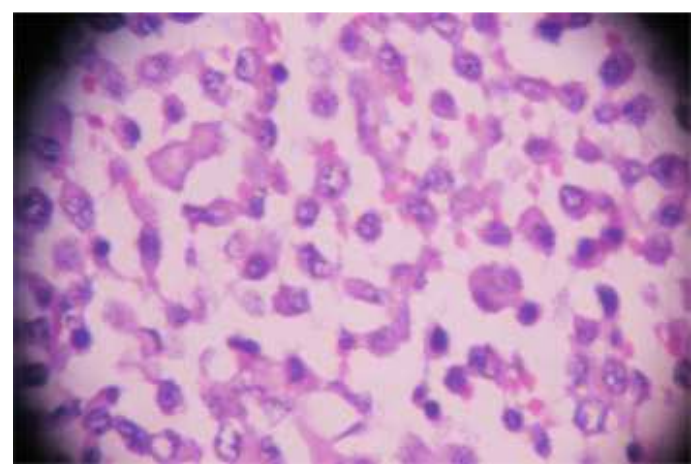

